\title{
APLICAÇÃO DO MAPEAMENTO DO FLUXO DE VALOR EM UMA INDÚSTRIA TEXTIL
}

Jordana Martins dos Santos (Centro Universitário Farias Brito - FBUni) jordanamar@gmail.com Mauricio Johnny Loos (Centro Universitário Farias Brito - FBUni) mauricioloos@ hotmail.com

\section{Resumo}

Este artigo apresenta o Mapeamento do Fluxo de Valor (VSM - Value Stream Mapping) como uma ferramenta que facilita a implementação dos princípios da Produção Enxuta em operações de manufatura. Com base nessa premissa, este trabalho teve o objetivo de propor a aplicação da metodologia do Mapeamento do Fluxo de Valor em uma indústria têxtil, que tinha a proposta de introduzir práticas enxutas em seu sistema de produção. Como ponto de partida, escolheu-se o processo de tingimento e acabamento de tecidos do tipo voil, que são utilizados como principal matéria prima para fabricação de cortina e artigos para decoração. Esta linha de produtos foi escolhida para o VSM por ser um dos principais produtos da empresa e, paralelamente, apresentar ineficiências significativas em seu processo produtivo, fato que lhe conferiu prioridade para a implantação da Manufatura Enxuta. Utilizando a abordagem metodológica do estudo de caso e o manual de aplicação do VSM proposto por Rother e Shook (2003), o processo foi mapeado em seu estado atual e projetado em seu estado futuro desejado, de forma a incorporar práticas de Produção Enxuta. Embora o estado futuro projetado ainda não tenha sido aplicado e não existam indicadores para uma avaliação definitiva, os resultados preliminares já demonstram o potencial de melhoria que as práticas enxutas representam para o processo atual. Dentre os resultados mais relevantes, destacam-se a melhoria dos tempos produtivos (lead time, esperas e processamento) e a redução dos níveis de estoques intermediários.

Palavras-Chaves: Produção Enxuta, Value Stream Mapping (VSM).

\section{Introdução}

Durante o século XX, surgiram diferentes modelos de gestão da produção que permanecem em evidência no século atual, sendo que a Produção Enxuta representa, seguramente, um dos modelos mais difundidos. A simplicidade de seus princípios, associada ao forte apelo para a eliminação de perdas nos processos produtivos, justificam, pelo menos em parte, o grande interesse da comunidade empresarial em torno do tema. No entanto, o entusiasmo inicial com 
os benefícios prometidos pela Manufatura Enxuta pode diminuir quando as empresas se deparam com a relativa escassez de metodologias práticas para sua implantação.

Uma das ferramentas que contribui para a redução da lacuna entre teoria e prática da Produção Enxuta é o Mapeamento do Fluxo de Valor (VSM - Value Stream Mapping), pois facilita a implementação dos princípios enxutos no chão-de-fábrica. Além de representar uma técnica alternativa para o mapeamento de processos, o VSM, tal como descrito por Rother e Shook (2003), vem acompanhado de uma metodologia completa para a implantação da Manufatura Enxuta. Baseado no conceito de agregação de valor, o VSM ajuda a projetar um "estado futuro" que corresponde à melhoria do "estado atual" de um processo por meio da aplicação das técnicas de Produção Enxuta.

Para demonstrar a facilidade desta ferramenta, este artigo apresenta um caso de aplicação do Mapeamento do Fluxo de Valor em um processo de fabricação de tecidos para decoração.

A estrutura do texto apresentado inclui uma breve revisão de literatura sobre a filosofia da Produção Enxuta e sobre o Mapeamento do Fluxo de valor e suas aplicações. Posteriormente, são relatados os procedimentos metodológicos que nortearam a coleta e a análise de dados, incluindo a descrição das etapas da metodologia do VSM. Em seguida, é apresentada a aplicação da ferramenta no processo de tingimento e acabamento de tecidos do tipo voil, que é o objeto de análise da pesquisa. Por fim, tem-se as considerações finais sobre o trabalho realizado.

\section{Revisão da literatura}

Nesta seção é apresentada uma revisão da literatura sobre Produção Enxuta e Mapeamento do Fluxo de Valor, para posteriormente realizar a análise dos dados do caso a ser apresentado.

\subsection{Produção enxuta}

O termo "Produção Enxuta" foi disseminado por Womack, Jones e Roos (1992), após relatarem os resultados de um amplo estudo na indústria automobilística mundial (International Motor Vehicle Program - IMVP) que identificou diferenças significativas de produtividade entre as empresas japonesas e as empresas ocidentais. Os autores observaram que, na verdade, essas diferenças não eram resultantes apenas de uma técnica específica de gestão de operações, mas de um sistema integrado de princípios e técnicas que vieram receber a impactante denominação de Produção Enxuta. 
Embora seus defensores frequentemente a apresentem como uma teoria recente, Holweg (2007) reconhece, analisando sob uma perspectiva histórica, que a filosofia da Produção Enxuta já estava presente na indústria japonesa muitos anos antes de sua disseminação no ocidente, tomando forma por meio do modelo de gestão que Ohno (1997) e Shingo (1996) denominaram de Sistema Toyota de Produção. Como se pode observar no trabalho desses autores, um dos pilares que sustentam o Sistema Toyota de Produção é o esforço contínuo para a eliminação de perdas nos processos produtivos. Seguindo essa lógica, Ohno (1997) e Shingo (1996) classificaram diferentes tipos de perdas em sete categorias, sendo:
a) Defeitos;
b) Excesso de produção ou Superprodução;
c) Espera;
d) Transporte;
e) Movimentação;
f) Processamento inapropriado;
g) Estoque.

Os sete tipos de perdas classificados por Ohno (1997) e Shingo (1996) deram origem a vários trabalhos que focalizaram a redução de perdas como uma meta da Produção Enxuta.

Embora a redução de perdas esteja no cerne da Produção Enxuta, ela de fato representa uma consequência da implantação de um conjunto mais amplo de princípios e técnicas.

De acordo com a definição proposta por Shah e Ward (2007, p. 791):
"A Produção Enxuta é um sistema sócio técnico integrado, cujo principal objetivo é eliminar os desperdícios por meio da redução ou da minimização simultânea da variabilidade de processos internos, de fornecedores e de clientes".

Nesse sentido, é importante que as empresas utilizem metodologias e ferramentas que permitam a implantação de práticas enxutas de forma integrada.

\subsection{Value stream mapping (VSM)}

O conceito de agregação de valor surge do esforço de redução de perdas preconizado pela Produção Enxuta e, consequentemente, a necessidade de separar as atividades que agregam 
valor das atividades que não agregam valor. Com base na premissa de que o fluxo de valor é representado pelo conjunto de ações existentes no processo produtivo que (agregando valor ou não) são responsáveis por levar o produto até o cliente, Rother e Shook (2003) apresentam o Value Stream Mapping (VSM) como uma ferramenta que dá suporte à estruturação de um sistema de Produção Enxuta.

De fato, o VSM é mais abrangente que uma técnica comum de mapeamento de processos, com procedimentos definidos e simbologia própria, mas representa uma metodologia de referência para a implantação da Produção Enxuta. Com esse objetivo, o MFV se preocupa em mapear os fluxos de materiais e de informações de um processo ou de uma cadeia de valor, descrevendo o estado atual do processo e orientando a obtenção de um estado futuro que inclui a adoção de práticas de Produção Enxuta.

Uma das vantagens defendidas por Rother e Shook (2003) é que o VSM reúne várias técnicas enxutas em torno de uma linguagem comum e, por isso, evita que a implantação da Manufatura Enxuta ocorra por meio de ferramentas isoladas que, sozinhas, têm um potencial limitado de melhoria do fluxo de valor. A simbologia do VSM foi desenvolvida de modo a facilitar a identificação dos desperdícios e suas fontes, o que reforça a sua contribuição para atingir as metas permanentes da Produção Enxuta.

Devido à sua versatilidade de aplicações, o Mapeamento do Fluxo de Valor não está restrito à análise de um processo industrial dentro de uma unidade fabril. Jones e Womack (2004) sugerem a aplicação da ferramenta para a análise do que eles denominam de fluxo de valor estendido. Para isso, os autores apresentam um manual completo de aplicação do VSM em cadeias de suprimentos, orientado para descrever o fluxo de valor desde a matéria-prima até o consumidor final.

O Mapeamento do Fluxo de Valor é uma ferramenta de melhoria contínua, pois como se observa na figura 1, ela cria um círculo virtuoso no qual após realizar as ações para atingir o mapa futuro, o mapa do estado futuro torna-se o mapa do estado presente e serão elaboradas novas ações de melhoria para atingir o novo mapa futuro, e assim se repete o ciclo, o qual costuma ter um tempo de 3 a 6 meses. Na Toyota este processo é atualizado a cada 3 meses (ROTHER; SHOOK, 2003). 
Figura 1- Etapas para Mapeamento do Fluxo de Valor

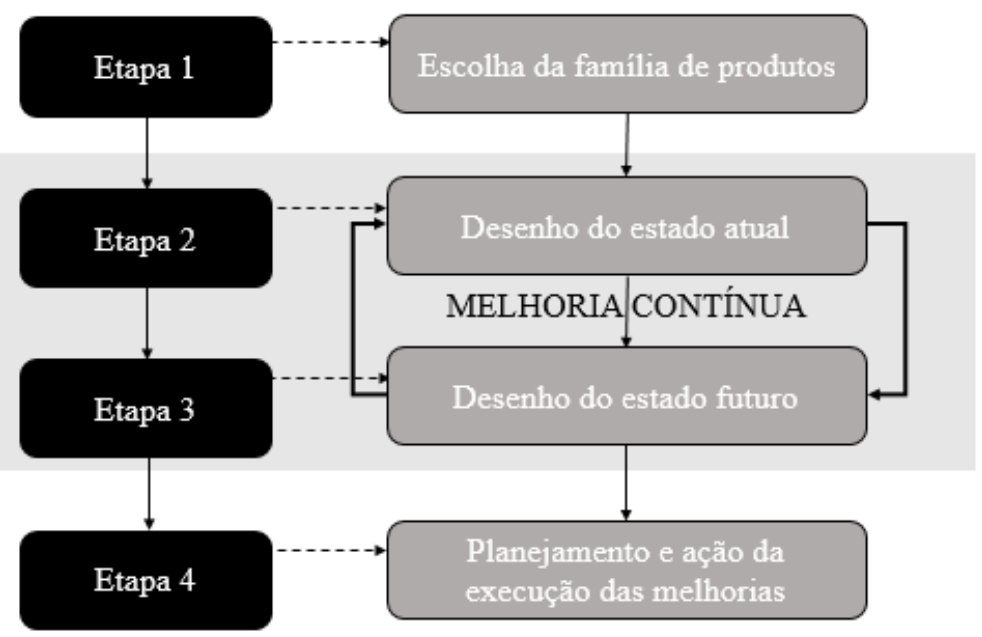

Fonte: Rother e Shook (2003).

De acordo com (ALVES et al., 2009) o VSM é uma ferramenta que, assim como as outras da Produção Enxuta, se concentra mais nas questões relativas à redução do lead time (tempo de ciclo) dos sistemas. O tempo de ciclo parece ser a principal e, às vezes, a única dimensão considerada neste tipo de ferramenta.

\section{Procedimentos metodológicos}

O presente trabalho tem como proposito avaliar, por meio da utilização da ferramenta VSM, o processo de tingimento de uma linha de produtos de uma indústria têxtil, confrontando os resultados de campo com a teoria vigente.

A metodologia de Mapeamento do Fluxo de Valor é composta por quatro etapas básicas, e neste trabalho foram empreendidas as 3 primeiras etapas, cuja aplicação é descrita na próxima seção do texto.

A seleção de uma família de produtos é necessária quando uma empresa possui diferentes fluxos de valor em relação a seu mix total de produtos. A formação de famílias utiliza o critério de similaridade de processos para agrupar produtos que passam por etapas de processamento semelhantes.

O mapa do estado atual (e também o mapa futuro) utiliza uma simbologia específica, que é caracterizada por ícones do fluxo de materiais, ícones do fluxo de informações gerais, conforme exposta no quadro 1. 
Quadro 1 - Ícones de materiais e de informação

\begin{tabular}{|c|c|c|c|c|c|c|c|c|}
\hline Símbolo & Nome & Nome & Símbolo & Nome & Função & Símbolo & Nome & Função \\
\hline \begin{tabular}{|l} 
MONTAGEM \\
\end{tabular} & Processo & $\begin{array}{l}\text { Demonstrar os } \\
\text { processos } \\
\text { existentes }\end{array}$ & & $\begin{array}{l}\text { Fluxo de } \\
\text { informação } \\
\text { Manual }\end{array}$ & $\begin{array}{l}\text { Indicar o fluxo } \\
\text { de informação } \\
\text { manual. }\end{array}$ & $40 s$ & $\begin{array}{l}\text { Linha do } \\
\text { tempo }\end{array}$ & $\begin{array}{l}\text { Registrar o Leadtime } \\
\text { de produção e os } \\
\text { tempos de } \\
\text { processamento }\end{array}$ \\
\hline$\underbrace{1}_{\substack{\text { EMPRESA } \\
X Y Z}}$ & $\begin{array}{l}\text { Fontes } \\
\text { Externas }\end{array}$ & $\begin{array}{l}\text { Representar } \\
\text { Clientes e } \\
\text { Fornecedores }\end{array}$ & & $\begin{array}{l}\text { Fluxo de } \\
\text { informação } \\
\text { eletrônica }\end{array}$ & $\begin{array}{l}\text { Indicar o fluxo } \\
\text { de informação } \\
\text { Eletrônica }\end{array}$ & & $\begin{array}{l}\text { Necessidade } \\
\text { de melhoria } \\
\text { (Kaizen) }\end{array}$ & $\begin{array}{c}\text { Indicar a necessidade } \\
\text { de melhoria em } \\
\text { processos específicos } \\
\text { para atingir o fluxo } \\
\text { desejado }\end{array}$ \\
\hline$T / C=45 \mathrm{seg}$. & \multirow{3}{*}{$\begin{array}{c}\text { Caixa de } \\
\text { dados }\end{array}$} & \multirow{3}{*}{$\begin{array}{l}\text { Registrar os dados } \\
\text { de um processo }\end{array}$} & \multirow{3}{*}{$\begin{array}{l}\text { Programacã̃o } \\
\text { semanal }\end{array}$} & \multirow{3}{*}{ Informação } & \multirow{3}{*}{$\begin{array}{l}\text { Descrever um } \\
\text { fluxo de } \\
\text { informação }\end{array}$} & \multirow{3}{*}{ ArM } & \multirow{3}{*}{$\begin{array}{c}\text { Verificar } \\
\text { (Programação } \\
\text { vá ver) }\end{array}$} & \multirow{3}{*}{$\begin{array}{l}\text { Indicar a necessidade } \\
\text { de verificar os níveis } \\
\text { de estoque para ajustar } \\
\text { a programação }\end{array}$} \\
\hline$T / R=30 \mathrm{~min}$. & & & & & & & & \\
\hline \begin{tabular}{|l|}
$2 \%$ Refug \\
$2 \%$ Refo \\
\end{tabular} & & & & & & & & \\
\hline$\sum_{\substack{300 \text { peças } \\
1 \text { dia }}}$ & Estoque & $\begin{array}{c}\text { Demonstrar } \\
\text { quantidade e o } \\
\text { tempo de cobertura } \\
\text { de estoque }\end{array}$ & & $\begin{array}{l}\text { Kanban de } \\
\text { Produção }\end{array}$ & $\begin{array}{l}\text { Dar permissão a } \\
\text { um processo de } \\
\text { quanto e o que } \\
\text { produzir }\end{array}$ & $\stackrel{\text { máx. } 20 \text { peças }}{\underset{\mathrm{FIFO} \longrightarrow}{\longrightarrow}}$ & $\begin{array}{c}\text { Fluxo } \\
\text { sequencial } \\
\text { (First in First } \\
\text { out) }\end{array}$ & $\begin{array}{c}\text { Representar a } \\
\text { transferência } \\
\text { sequencial de } \\
\text { quantidades } \\
\text { controladas } \\
\end{array}$ \\
\hline & Entregas & $\begin{array}{l}\text { Indica frequência } \\
\text { de entregas }\end{array}$ & & $\begin{array}{l}\text { Kanban de } \\
\text { retirada }\end{array}$ & $\begin{array}{l}\text { Dar permissão de } \\
\text { quanto e o que } \\
\text { pode ser retirado }\end{array}$ & & Supermercado & $\begin{array}{c}\text { Representar um } \\
\text { estoque controlado de } \\
\text { peças usado para puxar } \\
\text { a produção }\end{array}$ \\
\hline إسم & $\begin{array}{l}\text { Movimento } \\
\text { de material } \\
\text { empurrado }\end{array}$ & $\begin{array}{l}\text { Representar o } \\
\text { movimento de } \\
\text { materiais na } \\
\text { produção } \\
\text { empurrada }\end{array}$ & & $\begin{array}{l}\text { Kanban de } \\
\text { Sinalização }\end{array}$ & $\begin{array}{l}\text { Indicar quando o } \\
\text { ponto de } \\
\text { reposição é } \\
\text { alcançado em } \\
\text { kanbans por lote }\end{array}$ & & Operador & $\begin{array}{l}\text { Representar um } \\
\text { operador no seu posto } \\
\text { de trabalho }\end{array}$ \\
\hline 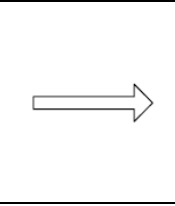 & $\begin{array}{l}\text { Movimento } \\
\text { de produtos } \\
\text { acabados e } \\
\text { de matéria } \\
\text { prima }\end{array}$ & $\begin{array}{c}\text { Representar o } \\
\text { movimento de } \\
\text { materiais do } \\
\text { fornecedor ou para } \\
\text { o cliente } \\
\end{array}$ & & $\begin{array}{l}\text { Bola para } \\
\text { puxada } \\
\text { sequenciada }\end{array}$ & $\begin{array}{l}\text { Dar permissão } \\
\text { para produzir uma } \\
\text { quantidade de } \\
\text { tipos pré- } \\
\text { determinados }\end{array}$ & & Retirada & $\begin{array}{l}\text { Indicar materiais sendo } \\
\text { puxados, geralmente } \\
\text { em um supermercado }\end{array}$ \\
\hline
\end{tabular}

Fonte: Adaptado de Rother e Shook (2003). 
Após elaborado o mapa do estado atual, deve-se incorporar as oportunidades de melhoria identificadas e desenhá-las no mapa de estado futuro. Para guiar a construção do mapa futuro e implantar práticas de Produção Enxuta, Rother e Shook (2003) sugerem uma lista de oito questões, apresentadas a seguir:

a) Questão 1. Qual é o takt time? O takt é o tempo disponível para a produção dividido pela demanda de mercado. É o responsável pela sincronização do ritmo de produção com o ritmo de demanda, determinado pelas necessidades dos clientes.

b) Questão 2. O produto será fabricado diretamente para a expedição ou para um supermercado de produtos acabados? Produzir diretamente para a expedição exige um fluxo de pedidos totalmente sincronizado com a entrega, de modo que não sejam formados altos níveis de estoque. Produzir para um supermercado significa produzir para um estoque pré-determinado e controlado, sendo que o produto somente será fabricado novamente quanto o supermercado necessitar.

c) Questão 3. É possível utilizar o fluxo contínuo? Fluxo contínuo é quando se consegue produzir uma peça de cada vez, com cada item passando imediatamente de um estágio para o seguinte, sem nenhuma parada entre eles.

d) Questão 4. Onde será necessário usar o sistema puxado com supermercado? Quando o fluxo contínuo não for possível, pode-se utilizar o sistema de supermercado com fluxo puxado via kanban. De modo alternativo, pode-se aplicar um sistema FIFO (first in, first out) entre dois processos, substituindo os supermercados por um fluxo controlado por meio de um armazém que limite a quantidade de estoque no processo seguinte.

e) Questão 5. É possível determinar o ponto da cadeia onde a produção deve ser programada? O ideal é, sempre que possível, enviar a programação de ordens de produção para um único ponto do processo puxador, preferencialmente localizado no fim da linha.

f) Questão 6. Como nivelar o mix de produção no processo puxador? Dentro da lógica heijunka, preconizada pelo sistema just-in-time de programação, recomenda-se distribuir uniformemente o mix de produtos em ordens de produção niveladas, de maneira que se possa reduzir lead time e estoques intermediários.

g) Questão 7. Quais melhorias de processos serão necessárias para atingir o estado futuro? 
h) Aplicar a melhoria contínua (kaizen) para identificar os pontos do processo que devem ser aperfeiçoados para viabilizar o estado futuro planejado.

Nesse contexto, este trabalho utiliza como abordagem metodológica o estudo de caso, segundo Yin (2001), o estudo de caso é caracterizado pelo estudo profundo e exaustivo dos fatos objetos de investigação, permitindo um amplo e pormenorizado conhecimento da realidade e dos fenômenos pesquisados.

\footnotetext{
"Um estudo de caso é uma investigação empírica que investiga um fenômeno contemporâneo dentro do seu contexto da vida real, especialmente quando os limites entre o fenômeno e o contexto não estão claramente definidos" (YIN, 2001 p. 33).
}

Yin (2001, p.28) considera o estudo de caso como uma estratégia de pesquisa que possui uma vantagem específica quando:

“Faz-se uma questão tipo 'como' ou 'por que' sobre um conjunto contemporâneo de acontecimentos sobre o qual o pesquisador tem pouco ou nenhum controle".

A seleção do objeto de análise (empresa) ocorreu devido a necessidade de a empresa reorganizar o seu processo industrial, tendo assim um cenário propicio para o desenvolvimento de um estudo de caso com aplicação de ferramentas estruturadas, nesse caso, o VSM.

Para a coleta de dados utilizou-se de entrevistas não estruturadas com os responsáveis diretos no processo de Planejamento e Controle da Produção, Processos Industriais e Expedição. O foco das entrevistas era entender as rotinas do processo, desde a colocação do pedido do cliente, até a sua expedição.

\section{Apresentação e discussão de resultados}

O detalhamento das etapas de aplicação do Mapeamento do Fluxo de Valor na empresa estudada está descrito a seguir.

\subsection{Aplicação do VSM}

O escopo produtivo analisado pertence ao processo de tingimento e acabamento de tecidos do tipo voil, destinados a venda para o segmento de decoração, sendo o principal insumo para fabricação de cortinas. Devido a um acordo de sigilo, foi decidido que o nome da empresa não seria divulgado neste artigo, e todos os dados que pudessem identificar a organização seriam omitidos. 


\subsection{Seleção de uma família de produtos}

Em função da diversidade de tipos de tecidos, composições, tipos de estampas e cores, hoje tem-se mais de 200 itens ativos em linha. Analisando a distribuição total dos itens, pode-se concluir que existem basicamente cinco famílias:

a) Família 1: Voil Tinto;

b) Família 2: Calandrado;

c) Família 3: Cetim;

d) Família 4: Estampado;

e) Família 5: Voil Cross;

Como mostra a figura 2, as cinco famílias foram formadas pelo agrupamento de itens que possuem etapas do processo em comum.

Figura 2 - Matriz produto x processo

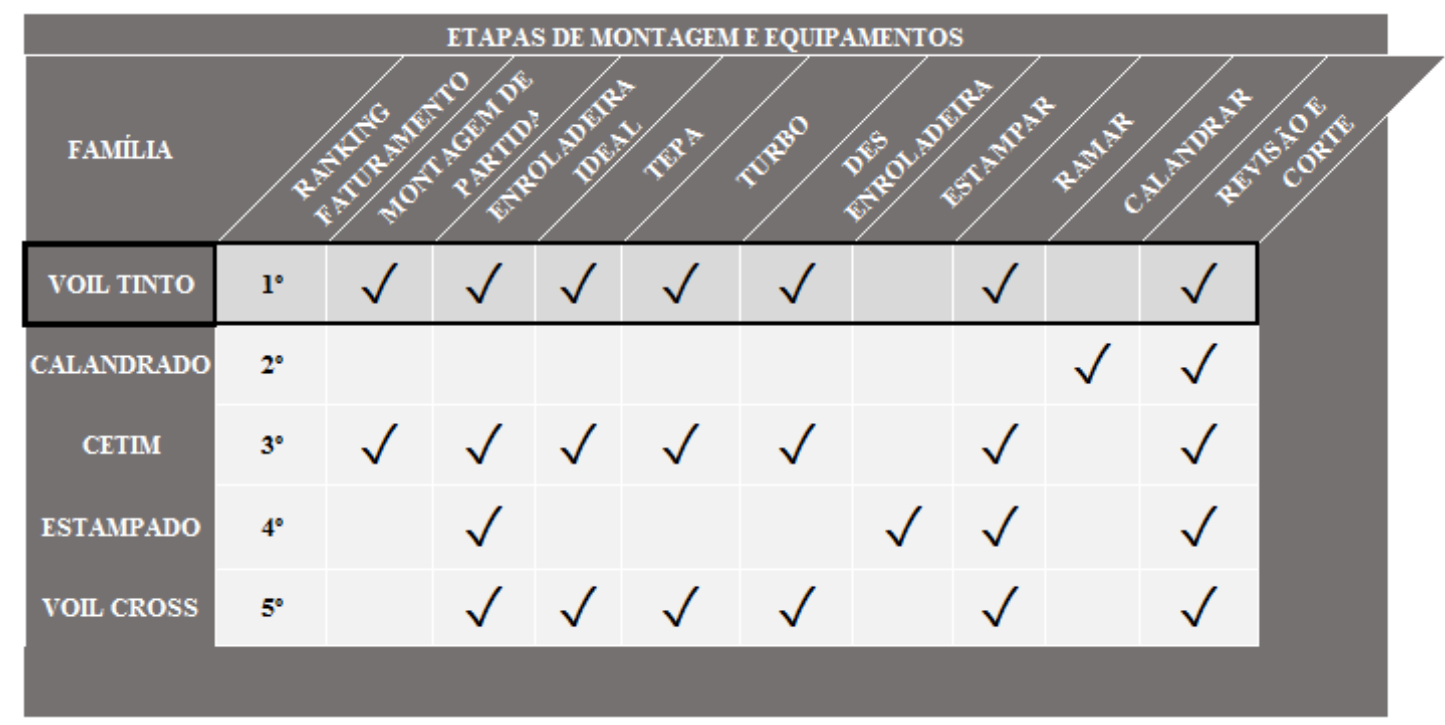

Fonte: Elaborado pelos autores.

Fazendo uma análise da importância das famílias do ponto de vista do faturamento e da variedade dos processos, observa-se que:

A família Voil Tinto possui uma variedade de processos igual ao da família Cetim, porém com a primeira posição no ranking de faturamento. Considerando essas informações, justifica-se a escolha da família Voil Tinto para o Mapeamento do Fluxo de Valor. 


\subsection{Mapa do estado atual}

Como mostra o mapa do estado atual, na figura 3, o processo inicia com a demanda enviada pelo cliente para o departamento Comercial. Essa demanda é enviada diariamente, e o comercial envia para o PCP (Planejamento e Controle da Produção) a previsão da demanda mensal e os pedidos diários.

Após liberadas as ordens de produção, o encarregado de produção coloca as mesmas nas respectivas máquinas e acompanha a produção de forma que cada etapa do processo consiga atender a data programada.

Figura 3- Mapa do estado atual

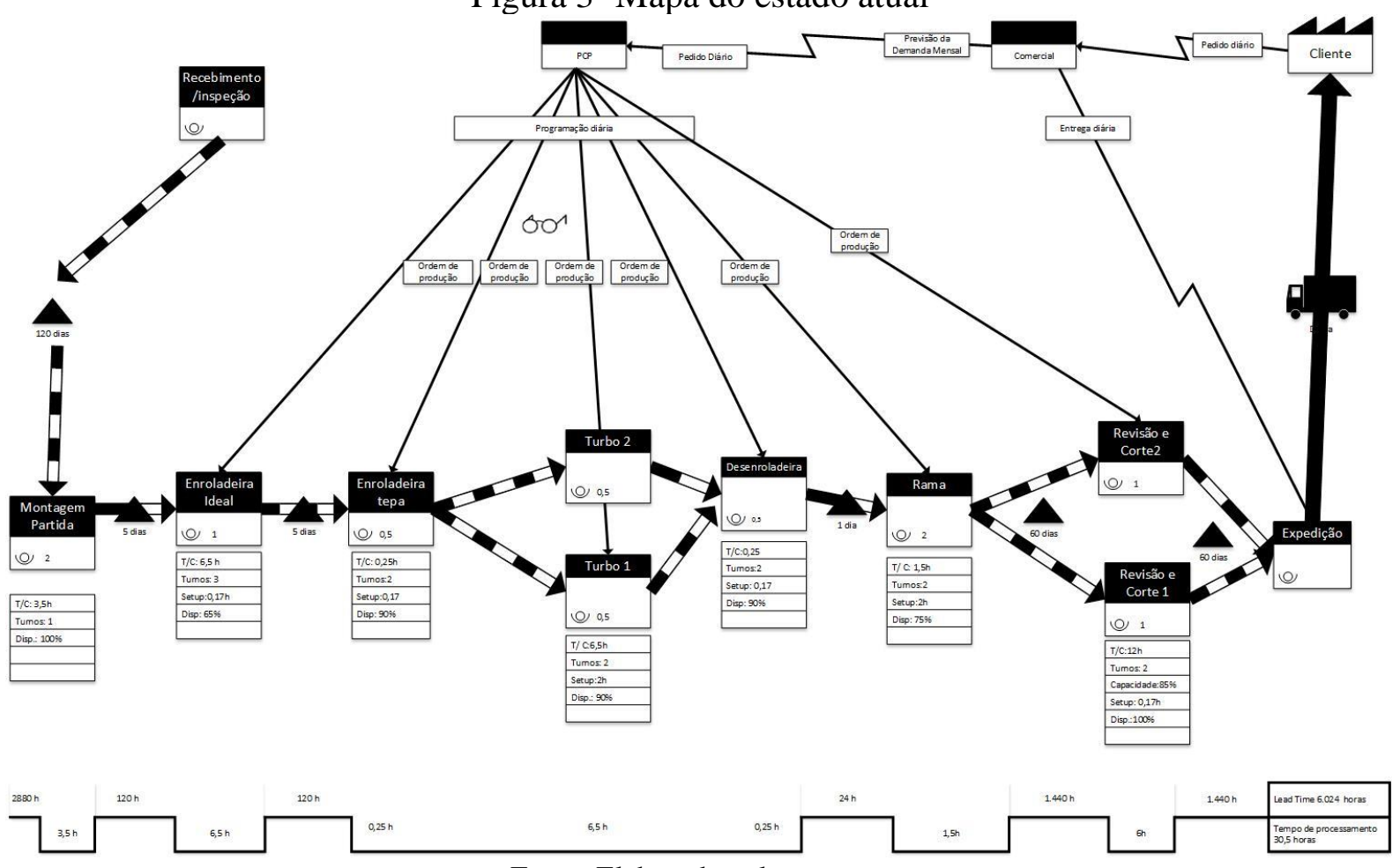

Fonte: Elaborado pelos autores

O Fluxo de materiais começa no estoque de tecidos crus (matéria prima), sendo que esses tecidos são enviados (empurrados) pelo setor de recebimento e inspeção.

O processo seguinte é a Montagem de Partida, o qual consiste em uma etapa completamente manual, onde 2 colaboradores efetuam a separação de peças de tecido (geralmente peças de 150 metros). Após efetuada a separação, eles acondicionam as peças em unitizadores padrão, onde totalizam aproximadamente 6.300 metros de tecidos, denominado de partida.

O segundo processo é a Enroladeira Ideal, um equipamento onde faz o enrolamento das peças de 150 metros e permite a utilização de uma máquina de costura para realizar a emenda do 
tecido, tornando uma partida de aproximadamente 6.300 metros, ficando esse rolo de tecido armazenado em cantilever.

O terceiro processo é a Tepa, outra máquina enroladeira, onde é necessário fazer o enrolamento do tecido em um carrinho específico para a etapa seguinte (Turbo).

O próximo processo é o tingimento Turbo, onde é realizado o tingimento do tecido. Para esse processo possui-se 2 Turbos, onde é possível realizar o tingimento de 2 lotes paralelos. A utilização de 2 equipamentos se faz necessária devido ao custo dos recursos necessários para seu funcionamento.

O quinto processo é a Desenroladeira, que possui a função inversa da Tepa (terceiro processo). Nessa etapa é realizado o desenrolamento do tecido, retirando do carrinho do Turbo e enrolando em outro carrinho, conhecido como carrolão.

O sexto processo é a etapa de Rama, onde o tecido é passado em um equipamento, onde são aplicados insumos para acabamento e realização da secagem do tecido. Após finalizado, o tecido fica armazenado em cantilever.

O sétimo e último processo é a Revisão e Corte, onde é realizada a revisão, corte das peças (padronizadas em 50 metros), etiquetagem e embalagem.

O tempo de ciclo (T/C) foi determinado em horas por lote de 6.300 metros. O sistema de produção no estado atual caracteriza-se de forma empurrada, ou seja, o PCP envia as ordens de produção para os postos de trabalho que produzem e "empurram" a produção para os processos subsequentes, cada qual tentando obedecer às datas programadas. Durante o estudo, foi identificada uma série de problemas acarretados pela programação empurrada, sendo:

a) A Montagem de Partida trabalha de acordo com o que recebe, sem saber se a etapa posterior tem capacidade de absorver a demanda;

b) Devido à dificuldade de preparação da máquina Turbo, o operador produz a sequência de ordens de fabricação que consome menos tempo de setup, não obedecendo às datas estipuladas nas ordens;

Os problemas identificados no mapa atual alertaram para a necessidade de se construir um estado futuro que pudesse melhorar o fluxo de valor e minimizar as perdas no processo. 


\subsection{Mapa do estado futuro}

Para a construção do mapa do estado futuro, foram analisadas as questões apresentadas na seção 3 .

Questão 1. Qual é o takt time?

O takt time foi calculado em uma demanda projetada de 14.500 metros/dia.

Considerando o tempo disponível e a demanda diária, obteve-se o takt time de 0,06 minutos, ou seja, a cada 0,06 minutos um metro de tecido deveria ser produzido.

$\mathrm{O}$ estado atual do processo tem um takt time maior e uma velocidade menor. Porém, com melhorias simples nos processos, o tempo de ciclo e o setup podem ser reduzidos e a velocidade média de processamento poderá ser facilmente aumentada.

Questão 2. O produto será fabricado para um supermercado de produtos acabados ou diretamente para a expedição?

Foi definido que a produção para a expedição continuará com fluxo empurrado. Apesar da inclusão de outra máquina no processo de Revisão e Corte e o tempo de ciclo estar satisfatório, é necessário manter o processo puxado para a expedição devido à instabilidade da demanda.

Questão 3. Onde se pode usar fluxo contínuo?

Analisando o fluxo atual, constata-se que o processo Desenroladeira possui um estoque de 1 dia. Este estoque é crítico, pois ao encerrar o processo de desenrolamento, o tecido ainda se encontra molhado, e caso o tempo de permanência nesse estoque seja superior a 1 dia, pode surgir problema na qualidade devido ao bolor que forma no tecido. Para o fluxo futuro, solucionou-se esse problema através do fluxo contínuo.

Questão 4. Onde será necessário usar o sistema puxado com supermercado?

O sistema puxado com supermercado será utilizado nos processos de Rama, Enroladeira Ideal e Montagem de Partida.

Questão 5. Em qual ponto da cadeia a produção deve ser programada?

O Processo puxador será o supermercado que abastece o processo de Revisão e Corte. Para poder puxar a produção, definiu-se o "Fitch" 6.300 metros. A produção só será puxada após a retirada de 4 cartões, que totalizam 25.200 metros, sendo esse o estoque necessário para partir 
a produção do Turbo. Conforme mencionado anteriormente, esse processo só é válido caso a produção seja de 2 ou mais equipamentos, devido ao custo e demanda de recursos.

Questão 6. Como nivelar o mix de produção no processo puxador?

O nivelamento será realizado através da demanda do PCP para o processo de Revisão e Corte.

Questão 7. Quais melhorias de processos serão necessárias para atingir o estado futuro?

a) Criar uma célula, com os processos Enroladeira Tepa, Turbo e Desenroladeira, remanejando a mão de obra sobressalente para outro setor;

b) Realização de um kaizen para redução dos defeitos no processo de Turbo;

c) Realização de um kaizen para reduzir o tempo de ciclo das máquinas da Revisão e Corte;

d) Criação do fluxo contínuo entre a Desenroladeira e a Rama, reduzindo o estoque;

e) Redução dos estoques intermediários através da criação de supermercados.

De acordo com a análise das questões acima, foi elaborado o mapa do estado futuro, tal como mostra a figura 4 .

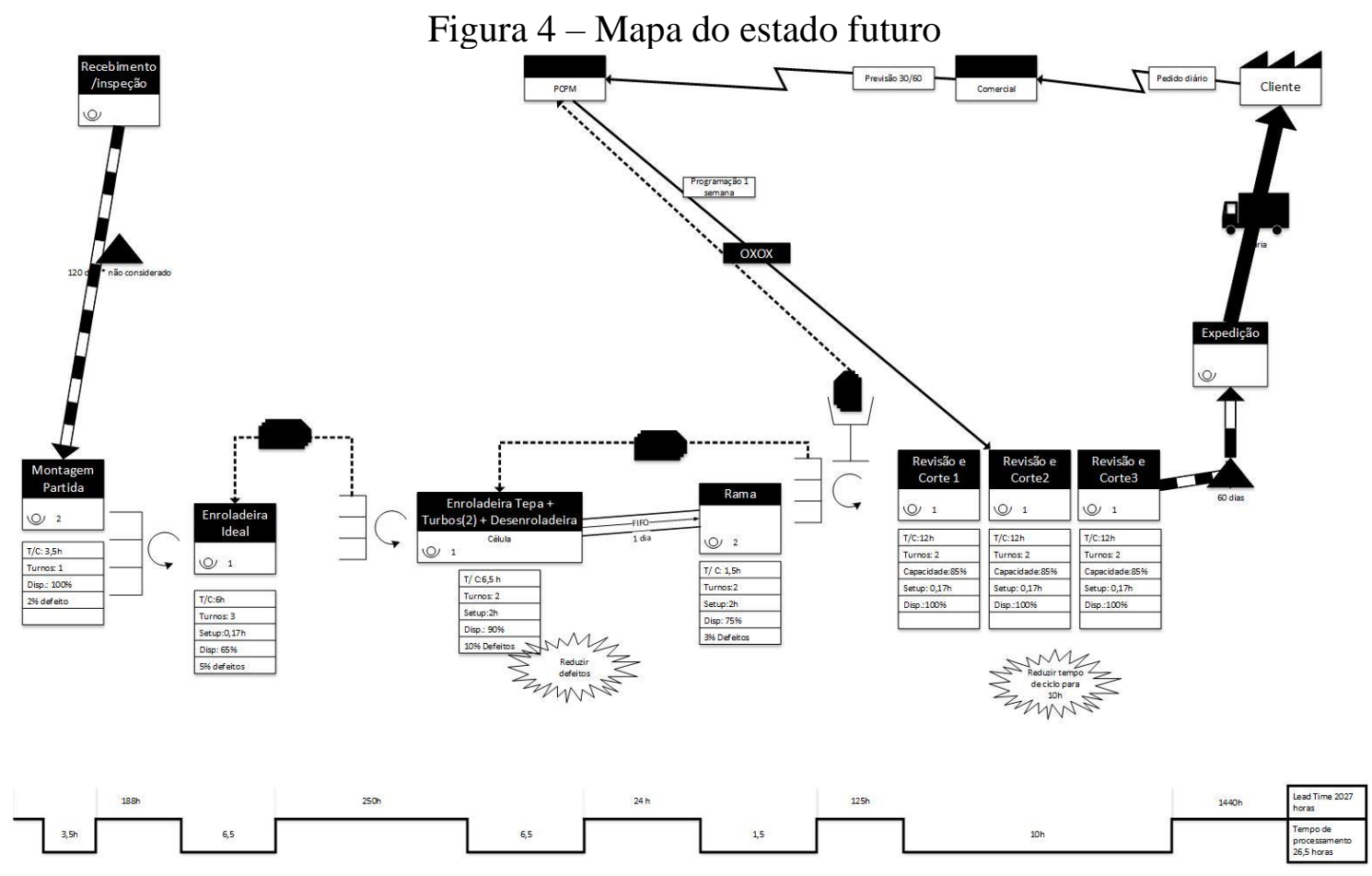




\subsection{Implementações e resultados}

Com base nas ações de melhoria que o estado futuro exigiu, foi elaborado um plano de trabalho que especifica metas, responsáveis e prazos para a implantação. O estado futuro ainda não foi implantado, porém, de uma forma geral, já é possível projetar uma avaliação preliminar dos resultados, apresentados no quadro 2, com base na comparação do estado futuro com o estado atual, considerando os dados coletados.

Quadro 2: Comparação dos resultados

\begin{tabular}{|c|c|c|}
\hline Indicador & Estado atual & Estado futuro \\
\hline Tempo de processamento & 30,5 horas & 26,5 horas \\
\hline Lead Time & 3.168 horas & 2.027 horas \\
\hline
\end{tabular}

Fonte: Elaborado pelos autores.

\section{Conclusões}

Este artigo apresentou o Mapeamento do Fluxo de Valor como uma ferramenta que pode guiar a implementação de práticas de Produção Enxuta em diferentes tipos de processos produtivos. Assim como em outras empresas que se intitulam "indústrias de processos contínuos", a fábrica analisada tem um fluxo de valor intermitente.

Ao atingir o objetivo deste trabalho, mapeando o fluxo de valor atual e projetando um estado futuro, pôde-se observar o grande potencial de melhoria que as práticas enxutas representam para o processo atual. Embora o estado futuro ainda esteja em planejamento de implantação, os resultados desenhados já demonstram a viabilidade para o processo dentro dos princípios enxutos.

Para a continuidade do trabalho realizado na empresa, o caminho natural é o planejamento e acompanhamento da implantação, por meio de revisões periódicas do fluxo de valor, tal como é recomendado pela metodologia original do VSM. Além disso, a aplicação da ferramenta poderia se estender para outros processos, ou mesmo procurar uma ampliação de escopo, ao mapear o fluxo de valor na cadeia de suprimentos.

\section{REFERÊNCIAS}

ALVES, J. R. X.; ALVES, J. M.; BERTELLI, C. R.. Redução do tempo de ciclo de importação de materiais através da aplicação do mapeamento do fluxo de valor. SIMPOI, Anais, 2009.

HOLWEG, M.. The genealogy of lean production. Journal of operations management, v. 25, n. 2, p. 420-437, 2007. 
JONES, D. T.; WOMACK, J. P.. Enxergando o todo: mapeando o fluxo de valor estendido. Lean Institute Brasil, 2004.

OHNO, T.. O sistema Toyota de produção além da produção. Bookman, 1997.

ROTHER, M.; SHOOK, J.. Aprendendo a enxergar: mapeando o fluxo de valor para agregar valor e eliminar o desperdício: manual de trabalho de uma ferramenta enxuta. Lean Institute Brasil, 2003.

SHAH, R.; WARD, P. T.. Defining and developing measures of lean production. Journal of operations management, v. 25, n. 4, p. 785-805, 2007.

SHINGO, S.. O sistema Toyota de produção. Bookman Editora, 1996.

WOOMACK, J.; JONES, D.; ROOS, D.. A Máquina que Mudou o Mundo, Rio de Janeiro. 1992.

YIN, R. K. Estudo de caso: planejamento e métodos. 2.ed. Porto Alegre: Bookman, 2001. 